SOCRATES

\title{
SOCRATES 2 (synopsis of Cochrane reviews applicable to emergency services)
}

\author{
P Gilligan, D Hegarty, A Khan, M Shepherd, G Lumsden, G Kitching, A Taylor, H Law, J Brenchley, \\ J Jones
}

"I myself know nothing, except just a little, enough to extract an argument from another who is wise and to receive it fairly". Socrates (399-469 BC)

r n this the second part of SOCRATES (synopsis of Cochrane reviews applicable to emergency services) the working party present the results of their search of the Cochrane Database of systematic reviews in the area of neurology. As previously noted, in the first article of this series, the work was undertaken to inform ourselves and our colleagues in emergency medicine about the reviews in the "Cochrane Database of systematic reviews" that are of relevance to emergency physicians. At the time this review was performed the 52 Collaborative review groups had produced 1750 articles of which we found 61 that were particularly relevant. This paper, as with SOCRATES, is aimed at disseminating a structured synopsis of the output of the Cochrane Database of systematic reviews of particular relevance to practising emergency physicians.

\section{Methodology}

The members of the 10 strong SOCRATES team were assigned Cochrane groups whose articles were of particular interest to them. Each reviewer then selected the articles from each of the Cochrane groups that they felt were relevant to emergency medicine. The reviewer then summarised the article using a format that had previously been agreed by the team. Each review was presented to the group. The full text of the article was then given to another group member and the accuracy of the synopsis assessed. Only completed reviews were considered for summarising as protocols (reviews in preparation) could not be used to give a definitive answer.

The structure of each synopsis is as follows:

- Title

- Background-information about the condition and question addressed by the review.

- Results-number of studies, number of patients.

- SOCRATES says-the answer to the clinically relevant question where available.

- Authors of the Cochrane review

The summaries were then grouped under various headings.

\section{PIRACETAM FOR ACUTE ISCHAEMIC STROKE}

Piracetam has neuroprotective and antithrombotic effects that may help to reduce death and disability in people with acute stroke. The objective of this review was to assess the effects of piracetam in acute presumed ischaemic stroke.

\section{Results}

Three trials with 1002 patients were included, with one trial contributing $97 \%$ of data.
Piracetam was associated with an increase in death, which was not statistically significant and the trend was not apparent after correction for stroke severity. Limited data showed no difference between treatment and control groups for functional outcome or dependency. One further trial of early piracetam use is ongoing (PASS II).

\section{SOCRATES says}

The data available do not support the use of piracetam in the treatment of patients with acute ischaemic stroke.

A Ricci S, Celani MG, Cantisani AT, et al. Piracetam for acute ischaemic stroke. Cochrane Library. Issue 4. Oxford: Úpdate Software, 2000.

\section{PENTOXIFYLLINE, PROPENTOFYLLINE, AND PENTIFYLLINE FOR ACUTE ISCHAEMIC STROKE}

Methylxanthine derivatives are vasodilators that also inhibit platelet aggregation and thromboxane A2 synthesis, decrease the release of free radicals, and may be neuroprotective. The objective of this review was to assess the effect of intravenous or oral methylxanthines in patients with acute ischaemic stroke.

\section{Results}

Five trials with 793 patients were included. There was no significant reduction in early death.

\section{SOCRATES says}

Pentoxifylline or propentofylline should not be used in the routine management of acute ischaemic stroke.

A Bath PMW, Bath FJ, Asplund K. Pentoxifylline, propentofylline and pentifylline for acute ischaemic stroke. Cochrane Library. Issue 4. Oxford: Update Software, 2000.

\section{PROSTACYCLIN AND ANALOGUES FOR ACUTE ISCHAEMIC STROKE}

Prostacyclin is an agent with a number of effects on platelets, blood vessels, and nerve cells, which might improve outcome after acute ischaemic stroke. The objectives of this review were to assess the effect of prostacyclin or analogues on survival in people with acute ischaemic stroke.

\section{Results}

Five trials with 191 patients were included. There was no significant reduction in the odds of early death with treatment but numbers were too small and design suboptimal to allow conclusions to be made.

\section{SOCRATES says}

Prostacyclin should not be used in the routine management of acute ischaemic stroke.

A Bath PMW, Bath FJ. Prostacyclin and analogues for acute ischaemic stroke. Cochrane Library. Issue 4. Oxford: Update Software, 2000. 


\section{CALCIUM ANTAGONISTS FOR ANEURYSMAL SUBARACHNOID HAEMORRHAGE}

Subarachnoid haemorrhage is an important form of stroke, particularly in younger patients. Death or disability occurs in $50 \%$, secondary ischaemia is believed to play an important part. Vasospasm is partly caused by an influx of calcium ions into vascular smooth muscle, giving the rationale for the use of calcium antagonists.

\section{Results}

Eleven randomised controlled trials in a total of 2804 patients. For death or disability number needed to treat $=$ 19 (95\% CI 11 to 53$)$. Death alone showed no statistically significant difference.

\section{SOCRATES says}

In a confirmed subarachnoid haemorrhage nimodipine reduces the proportion of patients suffering a poor outcome. The evidence for other calcium antagonists is inconclusive.

$\Delta$ Feigin VL, Rinkel GJE, Algra A, et al. Calcium antagonists for aneurysmal subarachnoid haemorrhage. Cochrane Library. Issue 4. Oxford: Update Software, 2000.

\section{ANTIFIBRINOLYTIC THERAPY FOR ANEURYSMAL SUBARACHNOID HAEMORRHAGE}

In subarachnoid haemorrhage (SAH) rebleeding is an important cause of morbidity and mortality. It is precipitated by lysis of the clot within the aneurysm. Antifibrinolytics such as tranexamic acid cross the blood brain barrier readily after SAH and so may be of use in the prevention of rebleeding.

\section{Results}

Eight randomised controlled trials on CT scan or CSF verified SAHS, five of which were double blinded were identified. A total of 937 patients were involved, tranexamic acid was by far the most commonly used agent. The risk of rebleeding was significantly reduced (OR 0.59, 95\% CI 0.42 to 0.81 ). All of the trials were over 10 years old. In that period the use of calcium antagonists has become widespread, these agents are believed to protect against cerebral ischaemia.

\section{SOCRATES says}

At present there is no indication to use antifibrinolytic treatment in SAH. However, this may change as further research becomes available.

\ Roos YBWEM, Rinkel GJE, Vermeulen $M$, et al. Antifibrinolytic therapy for aneurysmal subarachnoid haemorrhage. Cochrane Library. Issue 4. Oxford: Update Software, 2000.

\section{CORTICOSTEROIDS FOR ACUTE ISCHAEMIC STROKE}

One of the major causes of death in ischaemic stroke is cerebral oedema. Corticosteroids may reduce this oedema, but have potentially serious side effects.

\section{Results}

Seven randomised controlled trials in 453 patients. There was no significant increase in mortality associated with corticosteroid use (OR 1.08 95\% CI 0.68 to 1.72 ) and no change in the proportion of neurologically impaired survivors.

\section{SOCRATES says}

There is no indication to use corticosteroids in acute ischaemic stroke.

$\Delta$ Qizilbash N, Lewington SL, Lopez-Arrieta JM. Corticosteroids for acute ischaemic stroke. Cochrane Library. Issue 1. Oxford: Update Software, 2001.

\section{INTERVENTIONS FOR DELIBERATELY CHANGING BLOOD PRESSURE IN ACUTE STROKE}

Acute stroke (both ischaemic and haemorrhagic) is associated with hypertension in $75 \%$ of cases. Current guidelines suggest that hypertension should not routinely be treated in the acute phase, however these guidelines are not evidence based.

\section{Results}

Three double blind randomised controlled trials on a total of 133 patients, largely using calcium antagonists. Only one trial looked at mortality and showed no significant reduction in mortality (OR $0.65,95 \%$ CI 0.17 to 2.45 ) with nimodipine, hypertension in itself was not a prerequisite for inclusion in the trial.

\section{SOCRATES says}

There is insufficient evidence to support the use of antihypertensives in acute stroke.

$\Delta$ Bath $\mathbf{P}$, for the Blood pressure in Acute Stroke Collaboration (BASC). Interventions for deliberately altering blood pressure in acute stroke. Cochrane Library. Issue 1. Oxford: Update Software, 2001.

\section{CONCLUSION}

The Cochrane Collaboration continues to provide excellent rigorous systematic reviews to help inform our day to day practice. The amount of information available is enormous. The intention of the SOCRATES group was to summarise that information of particular relevance to practising emergency physicians. We hope that our synopsis of the Cochrane reviews applicable to emergency services in the area of neurology will be of use to our colleagues in emergency medicine and serve to help disseminate the excellent work of the Cochrane Collaboration.

\section{ACKNOWLEDGEMENTS}

We would like to thank Dr Richard Hardern and the staff of the Postgraduate Medical Library at the General Infirmary at Leeds for their support and technical advice in the preparation of this paper.

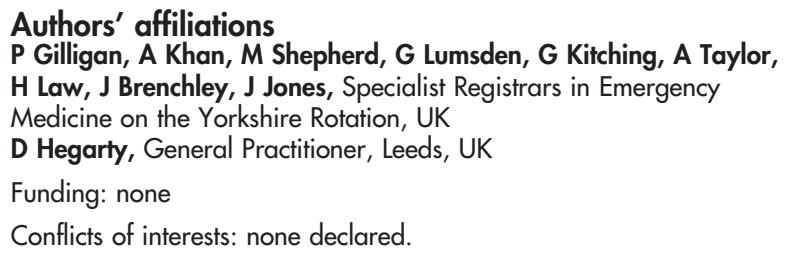

Correspondence to: Dr P Gilligan, 1 Far Moss, Alwoodley, Leeds LS17 7NU, UK; hegartydeirdre@ireland.com 